\title{
Cardiovascular Engineering in the First Decade of the 21st Century
}

John K-J. Li

(C) Springer Science+Business Media, LLC 2010

It was in the year 2000, at the turn of the 21 st century, my original idea to establish a forum for cardiovascular engineering professionals finally came to fruition. On the invitation of Kluwer Academic Press, the first issue of Cardiovascular Engineering: an International Journal began exactly a decade ago and it was an exciting moment. It has been an endeavor that has taken considerable effort and energy in maintaining timely publications of high quality articles in my role as the Editor-in-chief and in the fulfillment of the many authors' sense of accomplishment, seeing their research in print of a refereed journal.

The Journal was aimed at providing a forum to promote an international scholarly exchange among scientists, clinicians and biomedical engineers with a common interest in the cardiovascular field and with a particular emphasis on the utilization of quantitative and technological methodologies. As such, the Editorial Board members were recommended from nations in North and South America, Asia and Europe.

For any new journal to be longstanding and profitable for the publisher, a professional society affiliation is often necessary. Our Journal did not have this leisure. And it came half a decade later, after Springer took over Kluwer, to include the Journal in major citation bodies and providing us with paperless Electronic Manager for manuscript reviews. It has been the contributions from the many authors, as well as the capable effort of some of the editors, production editors and editorial assistants that made uninterrupted quarterly publication of the Journal possible over the decade.
In my appreciation, and if I could name a few individual Editorial Board members of their contributions, the late Prof. Leslie Geddes, the Presidential Medal of Technology recipient, would be the first. Known as the "Father of Cardiovascular Engineering", he paved the growth of the field of cardiovascular engineering for several decades. He gave his best support to the Journal and consistently contributing articles of new advances in technology for combating heart disease. We should all marvel his high energy and achievement. Prof. Abraham Noordergraaf, known as the "Father of Cardiovascular System Dynamics" has energized his European collaborators in making contributions to the Journal. Prof. YC Fung, known as the "Father of Biomechanics", has been a kind supporter of the Journal in its inception. So are the continued support from Dr. Peter Kerkhof, Dr. Max Valentinuzzi and Dr. John Clark. Guest editors of the Special Issues which have received high marks were attributed to the wonderful work of Dr. Jerry Batzel and his colleagues from the University of Graz.

I had planned to serve as the Editor-in-chief for just a few years, but it quickly turned into a decade. It is time for me to move on to publish my own research work in other highly ranked journals which have missed many of my publications in the past decade, as I chose to publish in Cardiovascular Engineering. I will also return to concentrate on my longneglected fondness of writing books. I will embark on new adventures of writing on exciting topics, and to continue to serve as World Scientific Publishers' Editor-in-Chief of Bioengineering and Biomedical Engineering Book Series.
J. K-J.Li ( $ه)$

Cardiovascular Engineering Lab, Department of Biomedical Engineering, Rutgers University, 599 Taylor Rd, Piscataway, NJ 08854, USA

e-mail: johnkjli@rci.rutgers.edu 